\title{
ANALISIS KARAKTERISTIK MARSHALL CAMPURAN AC-BC MENGGUNAKAN FILLER ABU TANDAN SAWIT DAN ABU BATU
}

\author{
Winayati \\ Program Studi Teknik Sipil Universitas Lancang Kuning \\ Jalan Yos Sudarso Km. 8 Rumbai Pekanbaru \\ E-mail : winayatimt@gmail.com \\ Fadrizal Lubis \\ Program Studi Teknik Sipil Universitas Lancang Kuning \\ Jalan Yos Sudarso Km. 8 Rumbai Pekanbaru \\ E-mail : fadrizal@unilak.ac.id
}

\begin{abstract}
Abstrak
Lapis aspal beton atau $A C$ (Asphalt Concrete) merupakan salah satu campuran beraspal dengan kekuatan campuran ditentukan oleh daya ikat (interlocking) antar agregat, bahan pengisi (filler) dan bahan pengikat (asphalt). Daya ikat antar agregat merupakan penyokong utama bagi kekuatan dan performa material pada struktur perkerasan. Oleh karena itu, permukaan jalan dapat menahan beban dengan baik ketika kendaraan melewatinya (Ahmad, 2010). AC-BC (Asphalt Concrete-Binder Course) adalah salah satu dari tiga macam campuran Asphalt Concrete, yaitu AC-BC (Asphalt ConcreteBinder Course), AC-WC (Asphalt Concrete-Wearing Course), AC-Base, perbedaan ketiga campuran ini terletak pada perbedaan ukuran bahan agregat yang digunakan sesuai dengan Spesifikasi Umum Bina Marga 2010. Pemilihan jenis material sebagai filler sangat penting karena filler merupakan bahan pengisi yang sifatnya halus dan dapat mengisi rongga atau pori yang mempunyai diameter lebih kecil atau kurang dari $0,002 \mathrm{~mm}$. Salah satu limbah yang dihasilkan oleh industri perkebunan kelapa sawit memberikan peluang alternatif material penyusun campuran aspal (filler). Sebagai gambaran umum bahwa pabrik yang mengolah kelapa sawit dengan kapasitas 200 ton TBS/hari akan menghasilkan abu tandan sawit sebesar 10,8\%/ hari (Fauzi dkk, 2002). Berdasarkan pengujian awal terhadap abu tandan sawit, dari analisis saringan diperoleh hasil bahwa abu tandan sawit $65 \%$ lolos saringan No.200, pada pengujian saringan basah dan penentuan indeks plastisitas filler abu tandan sawit telah memenuhi gradasai yang ditentukan. Selain aspal agregat kasar dan agregat halus, bahan pengisi (filler) adalah salah satu komponen dalam campuran yang mempunyai peranan besar pada sifat-sifat Marshall. Rekomendasi penelitian Afrian (2016), campuran $A C-B C$ yang memenuhi Spesifikasi Umum Bina Marga 2010, yakni 25\% filler abu tandan sawit dicampur dengan $75 \%$ abu batu dari berat total filler dalam campuran. Berdasarkan rekomendasi tersebut, penelitian dilanjutkan dengan analisis karakteristik Marshall campuran $A C-B C$ yang menggunakan komposisi campuran $50 \%$ filler abu tandan sawit dicampur dengan $50 \%$ abu batu, dengan menganalisis karakteristik Marshall, antara lain: stabilitas 920.118, flow didapat 3.7, VIM 4.006, VMA 15.930, MQ 240.722 juga masih memenuhi Standar Binamarga 2010.
\end{abstract}

Kata Kunci : Flow, IRS, Karakteristik Marshall, MQ, VFA, VIM, VMA 


\begin{abstract}
Concrete asphalt concrete is one of a mixture of asphalt with mixed strength determined by interlocking between the aggregate, filler and the asphalt. The aggregate bonding strength is a major contributor to the strength and performance of the material on pavement structures. Therefore, the road surface can withstand loads well when the vehicle passes by (Ahmad, 2010). AC-BC (Asphalt Concrete-Binder Course) is one of three AC mixes, AC-BC (Asphalt Concrete-Binder Course), AC-WC (Asphalt ConcreteWearing Course), AC-Base, the third difference of this mixture Lies in the difference in the size of the aggregate material used in accordance with the General Specification of Bina Marga 2010. The choice of material type as filler is very important because the filler is a filler that is smooth and can fill the cavity / pore that has a diameter smaller or less than 0,002 $\mathrm{mm}$. One of the wastes generated by the oil palm plantation industry provides an alternative opportunity for asphalt material mixer (filler). As a general illustration, a palm oil processing plant with a capacity of 200 tonnes of FFB/day will produce ash of palm bunches of 10,8\%/day (Fauzi et al., 2002). Based on preliminary testing of palm bunch ash, from the filter analysis, it was found that the ash of palm oil bunch $65 \%$ passed sieve No.200, in wet filter test and the determination of plasticity index of filler ash of palm bunches has fulfilled the specified gradation. In addition to the coarse aggregate asphalt and fine aggregate, the filler is one component in the mix that has a major role in Marshall properties. The Afrian research recommendation (2016), an AC-BC mix that meets the General Specification of DGH 2010, ie 25\% Filler ash of palm bunches mixed with 75\% Ash Stone from the total weight of filler in mixture. Based on these recommendations, the study continued with analysis of Marshall characteristics of AC-BC mixture using mixture composition of 50\% filler ash palm bunch mixed with 50\% Ash Stone, by analyzing Marshall characteristics, among others: stability 920.118, flow obtained 3.7, VIM 4.006, VMA 15.930, MQ 240.722 also still meet the Standard of Binamarga.
\end{abstract}

Keywords : Flow, IRS, Marshall Characteristics, MQ, VFA, VIM, VMA

\section{A. PENDAHULUAN}

Hasil penelitian Afriyan, karakteristik Marshall yang didapat dari penggunaan abu tandan sawit sebagai filler nilainya cenderung mengalami peningkatan dan memenuhi Spesifikasi Umum Bina Marga 2010, pada campuran dengan komposisi $25 \%$ filler abu tandan sawit dicampur $75 \%$ abu batu dari berat total filler dalam campuran. Variasi tersebut dalam campuran $A C-B C$ memenuhi standar karakteristik Marshall, dari rekomendasi ini, dilakukan penelitian lanjutan dengan menganalisis karakteristik Marshall campuran $A C-B C$ yang mengunakan komposisi campuran 50\% filler abu tandan sawit dicampur dengan $50 \%$ abu batu, antara lain : stabilitas, flow, melanjutkan penelitian dengan analisis karakteristik Marshall campuran $A C-B C$ yang mengunakan komposisi campuran $50 \%$ filler abu tandan sawit dicampur dengan 50\% abu batu, dengan menganalisis karakteristik Marshall, antara lain : stabilitas, flow, VIM (Void in the Compacted Mixture), VMA, VFA, MQ (Marshall Quotient), IRS (Index Retained Strength). 


\section{B. TINJAUAN PUSTAKA}

\section{Lapis Aspal Beton}

AC-BC (Asphalt Concrete-Binder Course) adalah salah satu dari tiga macam campuran $A C$, yaitu $A C-B C$ (Asphalt Concrete-Binder Course), ACWC (Asphalt Concrete-Wearing Course), AC-Base. Perbedaan ketiga campuran terletak pada perbedaan ukuran bahan agregat yang digunakan sesuai dengan Spesifikasi Umum Bina Marga 2010 (Bina Marga, 2010). Penggunan $A C-B C$ yaitu untuk lapis pondasi atas dalam perkerasan dan mempunyai tekstur yang agak kasar.

\section{Filler}

Bahan pengisi (filler) adalah bahan yang lolos ukuran saringan No.30 $(0,59 \mathrm{~mm})$ dan paling sedikit 65 $\%$ lolos saringan No.200 (0,075 mm) berdasarkan SNI 03-6723 (Standar Nasional Indonesia Spesifikasi Bahan Pengisi untuk Campuran Beraspal, 2002).

\section{Abu Tandan Sawit (ATS)}

Tandan sawit sebagai sisa pengolahan pabrik kelapa sawit dalam bentuk padat dibakar dan akan menghasilkan Abu Tandan Sawit. Adapun komposisi kimia abu tandan sawit ditunjukkan Tabel 1.

Tabel 1. Komposisi Kimia Abu Tandan Sawit (ATS)

\begin{tabular}{lc}
\hline \multicolumn{1}{c}{ Parameter } & Hasil analisis $(\boldsymbol{\%})$ \\
\hline Kalium $(\mathrm{K})$ & 25,8 \\
Silika $(\mathrm{Si})$ & 19,1 \\
Calsium $(\mathrm{Ca})$ & 2,7 \\
Magnesium $(\mathrm{Mg})$ & 2,8 \\
Natrium $(\mathrm{Na})$ & 0.03 \\
Posfat & 0,2 \\
Klor $(\mathrm{Cl})$ & 4,9 \\
CO3 & 9,2 \\
\hline
\end{tabular}

(sumber : Zahrina, 2007)

\section{Karakteristik Beton Aspal}

Suatu perkerasan harus memiliki karakteristik tertentu sehingga kuat menahan beban serta aman dan nyaman ketika dilalui kendaraan, (Putrowijoyo, 2006), yaitu :

a. Stabilitas (Stability)

The Asphalt Institute menyatakan bahwa stabilitas adalah kemampuan campuran aspal untuk menahan deformasi akibat beban yang bekerja, tanpa mengalami deformasi permanen seperti gelombang, alur ataupun bleeding dinyatakan dalam satuan $\mathrm{kg}$ atau $\mathrm{lb}$.
Nilai stabilitas diperoleh dari hasil pembacaan langsung pada alat Marshall Test sewaktu melakukan pengujian Marshall.

b. Kelelahan (flow)

Flow adalah besarnya deformasi vertikal benda uji yang terjadi mulai saat awal pembebanan sampai kondisi kestabilan maksimum sehingga sampel sampai batas runtuh dinyatakan dalam satuan mm. Nilai flow yang tinggi mengindikasikan campuran bersifat plastis dan lebih mampu mengikuti 
deformasi akibat beban, sedangkan nilai flow yang rendah mengindikasikan campuan tersebut memiliki banyak rongga yang tidak terisi aspal sehingga campuran berpotensi untuk mudah retak. Pengukuran flow bersamaan dengan pengukuran nilai stabilitas Marshall. Nilai flow juga diperoleh dari hasil pembacaan langsung pada alat Marshall Test sewaktu melakukan pengujian Marshall.

\section{c. Durabilitas (Durability)}

Durabilitas yaitu kemampuan suatu lapis perkerasan jalan untuk mempertahankan diri dari kerusakan atau mencegah keausan karena pengaruh lalu lintas, pengaruh cuaca dan perubahan suhu yang terjadi selama umur rencana. Faktor yang mempengaruhi durabilitas aspal beton adalah :

1). Selimut aspal yang tebal sehingga dapat menghasilkan perkerasan yang berdurabilitas tinggi, tetapi kemungkinan terjadi bleeding tinggi.

2). VIM (Void In Mix) kecil, sehingga lapis kedap air dan udara tidak masuk ke dalam campuran yang menyebabkan terjadinya oksidasi dan aspal menjadi rapuh.

3). VMA (Void in Material) besar, sehingga selimut aspal dibuat tebal. Jika VMA dan VIM kecil serta kadar aspal tinggi kemungkinan terjadi bleeding besar. Untuk mencapai VMA yang besar ini dipergunakan agregat bergradasi senjang.

d. Tahanan geser (Skid Resistance)

Skid resistance menunjukkan kekesatan permukaan perkerasan untuk mengurangi selip pada kendaraan saat perkerasan dalam keadaan basah atau kering. Hal ini terjadi karena pada saat terjadi hujan kekesatan pada lapis permukaan akan berkurang walaupun tidak sampai terjadi aquaplaning. Kekesatan dinyatakan dengan koefisien gesek antara permukaan jalan dan ban kendaraan. Faktor yang mempengaruhi tahanan geser adalah :

1). Penggunaan kadar aspal yang tepat sehingga tidak terjadi bleeding

2). Penggunaan agregat dengan permukaan kasar

3). Penggunaan agregat yang cukup

4). Penggunaan agregat berbentuk kubus

e. Fleksibilitas

Fleksibilitas pada lapisan perkerasan adalah kemampuan lapisan untuk mengikuti deformasi yang terjadi akibat beban lalu lintas berulang tanpa timbulnya retak dan perubahan volume. Fleksibilitas yang tinggi dapat diperoleh dengan:

1). Penggunaan agregat bergradasi senjang sehingga diperoleh VMA yang besar.

2). Penggunaan aspal lunak (aspal dengan penetrasi tinggi).

3). Penggunaan aspal yang cukup banyak sehingga diperoleh VIM yang kecil.

MQ (Marshall Quotient) merupakan parameter untuk mengukur tingkat fleksibilitas campuran. Semakin tinggi MQ, maka campuran lebih kaku berarti fleksibilitasnya rendah. Namun, jika MQ semakin kecil, campuran memiliki nilai fleksibilitas tinggi.

1). Porositas 
Porositas adalah kandungan udara yang terdapat pada campuran perkerasan. Porositas berfungsi untuk mengalirkan air permukaan secara sempurna bersamaan dengan kemiringan perkerasan sehingga dapat mengurangi beban drainase yang terjadi di permukaan.

2). Workability

Workability adalah kemudahan suatu campuran untuk dihampar dan dipadatkan sehingga memenuhi hasil yang diharapkan. Faktor yang mempengaruhi kemudahan dalam pelaksanaan adalah gradasi agregat, temperatur campuran dan kandungan bahan pengisi. Ketujuh sifat campuran beton aspal ini tidak mungkin dapat dipenuhi sekaligus oleh satu campuran. Hal ini sangat perlu diperhatikan ketika merancang tebal perkerasan jalan.Jalan yang melayani lalu lintas ringan seperti mobil penumpang sepantasnya lebih memilih jenis beton aspal yang mempunyai sifat durabilitas dan fleksibilitas yang tinggi daripada memilih jenis beton aspal dengan stabilitas tinggi.

\section{DATA DAN ANALISA DATA}

\section{Lokasi Penelitian}

Penelitian dilakukan di Laboratorium Dinas Pekerjaan Umum Provinsi Riau Bidang Unit Pelaksana Teknis (UPT) Pengujian yang beralamat di Jalan Sudirman No.197 Pekanbaru. Dengan dasar menggunakan sistem pencampuran aspal panas $A C-B C$ dengan panduan Spesifikasi Umum
Bina Marga 2010 yang merupakan dasar dari pembangunan jalan raya. Sedangkan standar-standar pengujian yang digunakan sebagian menggunakan standar dari metode-metode yang disahkan atau distandarkan oleh Bina Marga bahkan ada yang telah menjadi Standar Nasional Indonesia (SNI). Pengujian dalam penelitian ini dilakukan secara bertahap, yaitu terdiri atas pengujian agregat (kasar, halus dan filler), aspal dan pengujian terhadap campuran (uji Marshall).

\section{Metode Analisis Data}

Dalam melakukan penelitian ini dibutuhkan juga bahan dan alat bantu untuk pengolahan data sebagai berikut :

a. Perangkat Lunak (software)

Microsoft Excel digunakan sebagai alat bantu untuk menampilkan hasil analisa dari data yang ditampilkan dalam bentuk grafik dan pengkodean data.

b. Perangkat Keras (hardware)

Perangkat keras yang digunakan adalah timbangan, alat tulis, hand counter, material sample perkerasan AC-WC dengan 50\% ATS dan 50\% ATB sebanyak 15 sample digunakan untuk mendapatkan datadata karakteristik Marshall di laboratorium.

\section{HASIL DAN PEMBAHASAN}

Kinerja campuran $A C-B C$ menggunakan filler abu batu dan abu tandan sawit dengan persentasi 50\% $50 \%$ menghasilkan karakteristik marshall antara lain memiliki stabilitas, VIM, VMA, MQ, dan IRS menunjukkan nilai diatas nilai yang disyaratkan dalam Spesifikasi Umum Bina Marga 2010. 

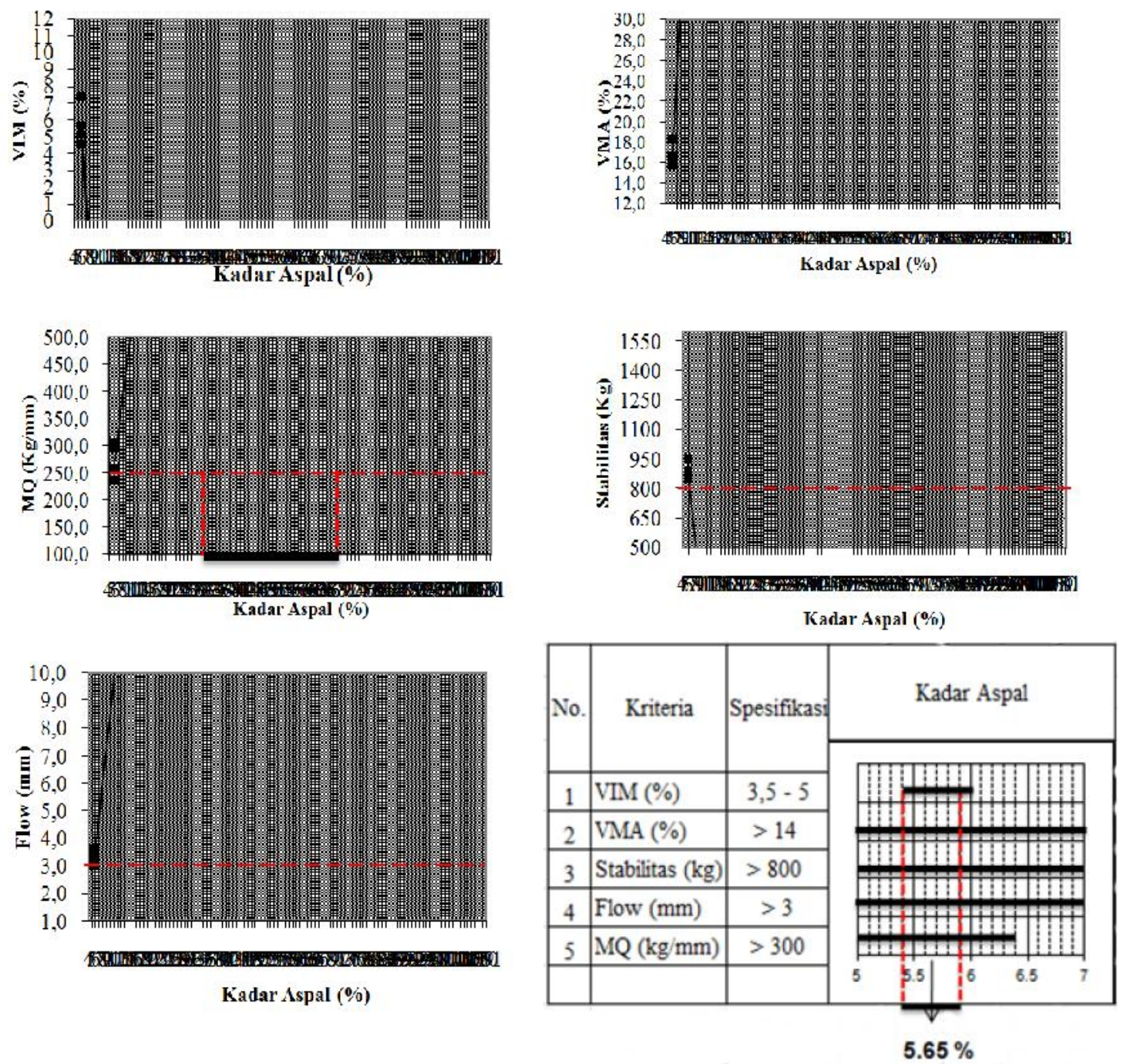

Gambar 2. Kadar Aspal Optimum

Hasil análisis karakteristik kadar aspal optimum untuk variasi filler 50\% abu batu : 50\% abu tandan sawit adalah berikut :

a. Rongga dalam Campuran (Void In Mix - VIM)

Rongga dalam campuran (Void In Mix - VIM) merupakan ruang udara yang ada di antara partikel agregat yang telah diselubungi oleh aspal di dalam campuran yang telah dipadatkan dan dinyatakan dalam persen dari volume total. Nilai VIM merupakan ukuran yang umum dikaitkan dengan durabilitas dan kekuatan dari campuran.Nilai VIM yang lebih kecil akan menyebabkan terjadinya bleeding yaitu keluarnya aspal kepermukaan perkerasan ACBC saat pemadatan oleh beban lalu lintas, sedangkan nilai VIM yang lebih besar menyebabkan campuran perkerasan AC-BC kurang kedap air sehingga mengakibatkan campuran cepat mengalami kerusakan.

Pertambahah kadar aspal akan menyebabkan semakin kecil nilai VIM, hal ini disebabkan aspal lebih banyak mengisi rongga-rongga dalam campuran sehingga ronggarongga didalam campuran perkerasan AC-BC semakin kecil. 
Spesifikasi Umum Bina Marga 2010 memberi batasan untuk VIM 3,5 $\mathrm{mm}$ dan maksimum $5 \mathrm{~mm}$, sedangkan hasilyang didapat VIM = 4,006 memenuhi standar.

b. Rongga dalam material VMA (Void in Material) besar, sehingga selimut aspal dibuat tebal. Jika VMA dan VIM kecil serta kadar aspal tinggi kemungkinan terjadi bleeding besar. Untuk mencapai VMA yang besar ini dipergunakan agregat bergradasi senjang. Spesifikasi Umum Bina Marga 2010 memberi batasan untuk VMA lebih besar dari 14, sedangkan hasil yang didapat VAM 15,930 memenuhi standar.

c. Stabilitas (Stability), The Asphalt Institute menyatakan bahwa stabilitas adalah kemampuan campuran aspal untuk menahan deformasi akibat beban yang bekerja, tanpa mengalami deformasi permanen seperti gelombang, alur ataupun bleeding dinyatakan dalam satuan $\mathrm{kg}$ atau $\mathrm{lb}$. Nilai stabilitas diperoleh dari hasil pembacaan langsung pada alat Marshall Test sewaktu melakukan pengujian Marshall. Stabilitas terjadi dari hasil geseran antar butir, penguncian antar partikel dan daya ikat yang baik dari lapisan aspal. Dengan demikian stabilitas yang tinggi dapat diperoleh dengan penggunaan agregat dengan gradasi yang rapat, agregat dengan permukaan kasar dan aspal dalam jumlah yang cukup, yang diperoleh $920.110 \mathrm{lb}$. d. Kelelahan (flow), flow adalah besarnya deformasi vertikal benda uji yang terjadi mulai saat awal pembebanan sampai kondisi kestabilan maksimum sehingga sampel sampai batas runtuh dinyatakan dalam satuan mm. Nilai flow yang tinggi mengindikasikan campuran bersifat plastis dan lebih mampu mengikuti deformasi akibat beban, sedangkan nilai flow yang rendah mengindikasikan campuan tersebut memiliki banyak rongga yang tidak terisi aspal sehingga campuran berpotensi untuk mudah retak. Pengukuran flow bersamaan dengan pengukuran nilai stabilitas Marshall. Nilai flow juga diperoleh dari hasil pembacaan langsung pada alat Marshall Test sewaktu melakukan pengujian Marshall, didapat nilai flow 3.7.

e. MQ (Marshall Quotient) merupakan parameter untuk mengukur tingkat fleksibilitas campuran.Semakin tinggi MQ, maka campuran lebih kaku berarti fleksibilitasnya rendah. Namun, jika MQ semakin kecil, campuran memiliki nilai fleksibilitas tinggi, 240.77 kurang dari standar.

\section{E. KESIMPULAN}

Dari penelitian campuran AC-BC yang memenuhi Spesifikasi Umum Bina Marga 2010, dengan persentasi campuran $50 \%$ filler abu tandan sawit dicampur dengan $50 \%$ abu batu dari berat total filler dalam campuran ACBC yang mempunyai karakteristik Marshall dapat dilihat pada Tabel 2. 
Tabel 2. Hasil Penelitian

\begin{tabular}{cccccccc}
\hline No. & $\begin{array}{c}\text { Persentase } \\
\text { AB-ABT }\end{array}$ & VIM & VMA & Stabilitas & Flow & MQ & VFA \\
\hline 1 & 5 & 6,440 & 16,051 & 837,523 & 3,3 & 254,67 & 59,875 \\
2 & 5,5 & 4,256 & 15,140 & 890,703 & 3,4 & 262,831 & 71,955 \\
3 & 6 & 3,586 & 15,608 & 959,765 & 3,6 & 266,333 & 77,047 \\
4 & 6,5 & 2,914 & 16,064 & 955,327 & 3,97 & 242,184 & 81,186 \\
5 & 7 & 3,035 & 17,197 & 797,275 & 4,5 & 177,595 & 82,363 \\
\hline & Rata-rata & $\mathbf{4 , 0 0 1}$ & $\mathbf{1 5 , 9 3 0}$ & $\mathbf{9 2 0 , 1 1 8}$ & $\mathbf{3 , 7 4}$ & $\mathbf{2 4 0 , 7 2 2}$ & $\mathbf{7 4 , 4 8 5}$ \\
\hline
\end{tabular}

\section{DAFTAR PUSTAKA}

Ahmad M., 2010, Kajian Karakter Indirect Tensile Strength Asphal Concrete Recycle dengan Campuran Aspal Penetrasi 60/70 dan Residu Oli pada Campuran Hangat, Skripsi Teknik Sipil, Universitas Sebelas Maret, Surakarta.

Bina Marga, 2010, Spesifikasi Campuran Beraspal Panas pada Spesifikasi Umum Jalan dan Jembatan Edisi 2010, Direktorat Jendral Bina Marga, Jakarta.

Bina Marga, 2003, RSNI-M-01 Metode

Pengujian Campuran Beraspal Panas dengan Alat Marshall, Pustran Balitbang Pekerjaan Umum, Jakarta.

Bina Marga, 2002, SNI-03-6723 Spesifikasi Bahan Pengisi xxuntuk Campuran Beraspal, Pustran Balitbang Pekerjaan Umum, Jakarta.

Bina Marga, 1991, SNI-06-6441 Metode Pengujian Kehilangan Berat Minyak dan Aspal dengan Cara A, Pustran Balitbang Pekerjaan Umum, Jakarta.

Fauzi Y., dkk, 2008, Kelapa Sawit. Penebar Swadaya, Jakarta.

Hatherly LW., Leaver PC, 1967, Asphaltic Road Materials, Edward Arnold Ltd, London.

Kerbs RD., Walker RD., 1971, Highway Materials, McGraw Hill, New York.
Sentosa L., 2006, Penggunaan Abu Gambut Sebagai Filler pada Campuran Lapis Aspal Beton dengan Pengujian Marshall, Jurnal Media Teknik Sipil, Universitas Riau, Pekanbaru.

Standar Nasional Indonesia, 2008, SNI 1969 Cara Uji Berat Jenis dan Penyerapan Air Agregat Kasar, Badan Standarisasi Nasional, Jakarta.

Sukirman S., 2003, Perkerasan Lentur Jalan Raya, Nova, Bandung.

Sukirman S., 2003, Beton Aspal Campuran Panas, Granit, Jakarta.

Mutohar Y., 2002, Evaluasi pengaruh Bahan Filler Fly Ash Terhadap Karakteristik Campuran Emulsi Bergradasi Rapat (CEBR), Tesis Magister, Universitas Diponegoro, Semarang.

Putrowijoyo R., 2006, Kajian Laboratorium Sifat Marshall dan Durabilitas Asphalt ConcreteWearing Course (AC-WC) dengan Membandingkan Penggunaan antara Semen Portland dan Batu sebagai Filler, Tesis Magister, Universitas Diponegoro, Semarang.

Zahrina I., 2007, Pemanfaatan Abu Sawit dan Cangkang Sawit Sebagai Sumber Silika pada Sintesis ZSM-5 dari Zeolit Alam, Jurnal Sains dan Teknologi. Universitas Riau, Pekanbaru. 